\title{
EL MILITARISMO O EL PODER MILITAR
}

\author{
Faustino Luna Farfán
}

\begin{abstract}
"Entre el que es guerrero y el que no lo es, no hay ninguna proporción; y no es razonable que quien está armado obedezca gustosamente al que está desarmado y que el desarmado se encuentre entre servidores armados. Pues, habiendo en el uno desdén y en el. otro sospecha, no es posible que realicen juntos buenas operaciones. Por otra parte un principe que no entiende nada de guerra, además de las otras calamidades, (...), no puede ser apreciado por sus soldados, ni fiarse de ellos."
\end{abstract}

Maquiavelo

\section{Su CARÁCTER INDEFINIBLE}

En el Diccionario Enciclopédico Cabanellas', leemos un esbozo de la definición de militarismo:

"Configura intromisión o acción excesiva de los militares en la política, en los negocios públicos o en la organización social, con abandono de sus específicas funciones de disponer la defensa nacional o con peligrosa acumulación de unas y otras tareas; este crecimiento [...] anormal de las instituciones militares las conduce a rebasar su función específica: la defensa del territorio nacional; $y$, si acaso, la expansión a costa de los vecinos débiles, pero nunca la sujeción de sus propios compatriotas."

El mismo diccionario ofrece como dato sorprendente: "Ia Academia definía a esta tendencia cual predomimio del elemento militar en el gobierno estatal, cuando en verdad se trata del ejercicio sin más del poder público o mediante un delegado incondicional..." $T$ todaría agrega: Parece oportuno recordar que Almirante en su notable Diccionario Militar, al Llegar a esta palabra, insertaba una definición muda reducida a estos simples signos ortográficos „i...??!!"”

Nos hacemos cargo de explicar que tales reservas en definir el militarismo se deben a su impronta impredecible como poder político de facto, que en cualquier parte y en cualquier momento puede irrumpir en el escenario socio-político de los pueblos, quebrar su orden jurídico y alterar su institucionalidad. Es decir, el militarismo como clase profesional es todavía imprevisible e ingobernable.

\section{Algo DE SU HISTORIA}

Las fuerzas armadas no están reconocidas como un elemento constitutivo del Estado que según la doctrina política clásica se compone de: territorio, pueblo, y poder iuris; no obstante, devienen en su componente indispensable, pues como advierte Smith (1995: 27) "El militarismo más que un sistema formal de pensamiento, es un tipo de opinión pública y como tal se halla presente en algún grado en cada sociedad. Y no se conoce pueblo o cultura que hubiere carecido de un ejército, con excepción singularísima de los Brahamanes, un pueblo de la India, que según refiere Voltaire (1981: 155) no ha formado jamás al frente de alguna bandera para ir a pelear y a destruir los pueblos inmediatos, porque su casta que es antiquísima, sus buenas costumbres y su religión estaban de acuerdo en no derramar jamás sangre ni aún de los animales inofensivos; pero por eso mismo, fueron subyugados con facilidad y lo serán siempre. Roma privilegió a su organización militar parangonándolo con el Derecho, porque, en palabras de Justiniano (Institutas 1986: preámbulo):

"La majestad imperial debe apoyarse sobre las armas y sobre las leyes, para que el Estado sea igualmente bien gobernado durante la guerra y durante la paz; para que el príncipe, rechazando en los combates las agresiones de sus enemigos, y ante la injusticia de los ataques de los hombres inicuos, pueda mostrarse tan religioso en la observancia del derecho como grande en los triunfos".

Pcro ningún griego ni romano se sustrajo al ejercicio militar; sus propios destacados filósofos destacaron tanto en las disciplinas olímpicas

1. Diccionario Enciclopédico de Derecho Usual. Guillermo Cabanellas. Edit. HEI ISTA, Buenos Aires 1982. 
como en el ejercicio y la estrategia militar². La diferencia entre uno y otro militarismo estuvo en que los griegos, particularmente los atenienses, evitaron siempre las fuerzas militares regulares, con excepción de Macedonia con Filipo II en su afán expansivo, y Esparta, que se organizó como Estado Guarnición. El ejercicio corporal era para las griegos (gímnica, equitación, maniobras de guerra etc.) rutina de vida y base del cultivo de la mente. La defensa permanente de la patria y aún la ofensa ocasional a las potencias extranjeras quedaba a cargo de sus milicias a cuya cabeza colocaban a un general, elegido sólo para la ocasión, de preferencia entre los campeones coronados en los Juegos Olímpicos. No obstante, mantuvieron a raya los afanes expansionistas de Filipo II y constituyeron un ejército invencible ante Darío y Jerjes, en que los griegos triunfaron sobre una fuerza invasora persa mil veces superior (Herodoto: Libro 8vo, Urania). Y no por eso, su responsabilidad y sus fracasos como sus éxitos eran considerados menos: "También se decidió que los generales se sometieran a juicio por sus actos durante todo el tiempo pasado. Verificado el juicio, Filesio y Janticles, tuvieron que pagar veinte minas que faltaban del dinero de la marina confiado a su custodia y Soféneto diez minas, porque, habiendo sido elegido jefe, se había descuidado."

Cuando el inconmensurable ejército persa, según la historia contada por Herodoto, es contenido aunque momentáneamente en el "Paso de Las Termopilas" por Los Trescientos encabezados por Leónidas, Jerjes, luego de disponer lo concerniente a sus muertos, los cuales eran veinte mil, interroga a unos hombres de Arcadia que sus servidores le llevan a su presencia, sobre qué hacían los griegos después de aquel combate encarnizado; ellos contestaron que celebraban las olimpiadas y contemplaban un certamen gimnástico e hípico. Entonces el persa les preguntó que cuál era el premio por el que contendían; ellos le hablaron de la corona de olivo que allí se da y dijo delante de todos: "Ah Mardonio, contra qué hombres nos llevaste a combatir, hombres que no contienden por dinero, sino por mérito!"
Roma, a diferencia de Grecia, profesionalizó su ejército desde el dictador Lucio Cornelio Sila (138-78 a. G) como instrumento de sus guerras de conquista. Era un ejército pagado, con derecho al botín de guerra y a la jubilación; como lo fue también el ejército de Alejandro; pero apenas les faltara esos estímulos podían tornarse en un ejército indisciplinado y peligroso capaz de negociar hasta la propia autoridad imperial.

\section{EL MILITARISMO CONTEMPORÁNEO}

Las dos grandes revoluciones de finales del siglo XVIII, la norteamericana y la francesa, que marcaron el inicio de la época contemporánea, cautelaron en sus constituciones la existencia de un ejército eficiente y disciplinado subordinado al poder civil. La "Declaración de Derechos de Virginia", aprobada el 12 de junio de 1776, dispuso en su Art. XIII:

"Una milicia bien regulada, reclutada entre el pueblo, entrenada en el manejo de armas, es la defensa adecuada, natural, y segura de un Estado libre; los ejércitos permanentes en tiempo de paz deben evitarse como peligrosos para la libertad; y en todo caso las fuerzas armadas estarán bajo la estricta subordinación y gobierno del poder civil."

Aprobada en Filadelfia, la Constitución norteamericana de 1787 , la única que por lo demás sigue rigiendo aquel país, al advertirse que no se había consagrado constitucionalmente aquella disposición declarativa, mediante la Segunda Enmienda, -de las diez incorporadas el 15 de diciembre de 1791- proclamaron: "Siendo necesaria una milicia bien ordenada para la seguridad de un Estado Libre, no se violará el derecho del pueblo a poseer y portar armas". 3 Alexander Hamilton abogando por la consagración constitucional de la milicia (Gitado por Smith: 380), dijo entonces:

"Una milicia bien disciplinada no sólo disminuirá la necesidad de instituciones militares, sino que, si las circunstancias obligarán en algún momento al gobierno a organizar un ejército de cierta magnitud, este ejército no podría nunca amenazar las libertades del pueblo mientras exista un gran cuerpo de ciudadanos, si bien pequeño e inferior en disciplina y en el empleo de

2. Jenofonte, discípulo de Sócrates, que en el 401 a.C, pasó a Persia como uno de los 13,000 mercenarios griegos que auxiliaban a Ciro El Joven, caracterizó en tres tipos a los jefes que conoció: "Clearco, el jefe de las más extremadas condiciones militares y de una desmesurada afición a la guerra, su temperamento militar se revelaba en la pasión por los peligros[...]". "Próxenos, el jefe honorable y justo, pensaba que el poder y la riqueza era necesario obtenerlos por medios justos y honorables y únicamente por ellos." Menón, el jefe bribón, consideraba que el camino más corto era el perjurio, la mentira y el engaño; un proceder sencillo y recto era según él una pura necedad[...]”. (Anábasis, Cap.VI, Libro Segundo).

3. El pueblo norteamericano, formado bajo esos principios constitucionales, siempre está dispuesto a servir en sus fuerzas armadas, y se considera un deshonor el rehusarse. Los candidatos a puestos públicos exhiben en lugar destacado de su hoja de vida su experiencia cívico-militar. 
las armas, que permanezca pronto a defender sus propios derechos y el de sus conciudadanos. Me parece que éste es el único sustituto que podemos idear para un ejército permanente y la mejor seguridad contra él, si existiera".

A su vez, el Acta Constitucional francesa de 1793 aseguró igualmente en tres disposiciones claves, la defensa nacional y la subordinación del poder militar al poder civil:

'Art.107', La fuerza general de la República está compuesta por el pueblo en su totalidad".

"Art.109", Todos los franceses son soldados, todos se ejercitan en el manejo de las armas".

"Art.1140, Ningún cuerpo armado puede deliberar."

En el derecho británico (Smith: 335), las reglamentaciones esenciales para la disciplina militar son reunidas en una ley del ejército, originalmente conocida como la Ley del Motín, que debe ser renovada anualmente desde que las reglamentaciones se adoptan sólo por el lapso de un año. Esto significa que la disciplina militar no tendría una base legal y que el ejército se disolvería, a menos que la ley tenga su prórroga anual en el parlamento. Esta ley, comparable en su significación al control sobre los cordones de la bolsa, ha sido considerada uno de los grandes fundamentos sobre la que ha descansado la supremacía civil en la Gran Bretaña, y que ha evitado los peligros de los ejércitos permanentes y su politización.

Con estas noticias preliminares, queremos significar que los estados independientes, indistintamentede sus formas degobierno, buscaron desde el inicio asegurar su continuidad y fortaleza uniendo pueblo y ejército en la tarea constante de la defensa; propósito que nunca abandonaron esos mismos Estados que hoy representan las sociedades más avanzadas y las mayores potencias bélicas; y, que en el caso de Francia, el pueblo demostró ser su exclusivo salvador frente a la guerra de conquista nazi. Cuando el 16 de junio de 1940 Francia se declaró vencida ante Alemania y aceptando sus alevosas condiciones de armisticio, consintió en dividir su territorio en dos zonas: una ocupada bajo la autoridad militar alemana y la otra libre. La resistencia civil francesa se organizó entonces en la Legión de Combatientes que en 1941 fue remplazada por la Legón de Combatientes y de Voluntarios de la Revolución Nacional; luego, la Legión Tricolor para la Reconquista. El 17 de mayo de 1944 las tropas aliadas llegaron a Orleáns, noticia que determinó en París la insurrección organizada por la resistencia y apoyada por la fuerza de la policía. La lista de los caídos superó los 150 mil soldados y 450 mil civiles. (Historia Universal de Jacques Pirenne, v. 11 ).

John Reed (1985:137) llama El Sueño de Francisco Villa al pensamiento del gran líder revolucionario mexicano quien apostaba por la supresión del ejército profesional, y su remplazo por las milicias cívicas:

"Cuando se establezca la nueva República, no habrán más ejércitos en México. Los ejércitos son los más grandes apoyos de la tiranía [...] Serán establecidas en toda la República colonias militares formadas por veteranos de la Revolución. El Estado les dará posesión de tierras agrícolas y creará grandes empresas industriales para darles trabajo. Laborarán tres días de la semana y lo harán duro, porque el trabajo así produce buenos ciudadanos. En los otros días recibirán instrucción militar lo que a su vez instruirán a todo el pueblo. Entonces cuando la Patria sea invadida, únicamente con tomar el teléfono desde el Palacio Nacional de México se levantará todo el pueblo mexicano desde los campos y las fábricas, bien armado, equipado y organizado para defender a su hogar. Mi ambición es vivir mi vida en una de esas colonias $[\ldots] "$

\section{LA MILIGIA GÍvIGA Y EL EJÉRGITO PROFESIONAL}

En el Perú independiente, no obstante que fueron las milicias las que desgastaron el poder colonial, como también constituyeron la columna vertebral del Ejército Libertador, así como lo fueron en el decisivo Combate del 2 de mayo de 1866 en que el coloniaje español fue definitivamente derrotado, la profesionalización de las FF.AA. y la extinción de las milicias cívicas, ha seguido un curso sinuoso en tres etapas: la primera, caracterizada por el reconocimiento de la importancia de la milicia, la segunda y tercera, dirigidos paulatinamente a suprimirla, para dejar a la Nación enteramente dependiente del ejército profesional y la policía uniformada.

Inaugurando la primera etapa y acorde con la innegable importancia de la milicia por sus actuaciones durante la guerra independentista, el Reglamento Provisional de 1821, dictado por el General José de San Martín, consideró entre sus atribuciones de Protector, "...proponer la creación de nuevos cuerpos de milicia, arreglar su economía interior, y hacer. las propuestas de oficiales a la capitanía general." 
Consecutivamente, la Constitución de 1823, la primera en ser debatida por una Asamblea Constituyente, dispuso en su artículo $165^{\circ}$, "Constituven la fuerza armada de tierra, el jejercto de línea, la milicia círica, y la guardia de policia."

Las Constituciones de 1826, (Art. $136^{\circ}$ ) y la de 1828, (Art. 146"), dispusieron a su turno: "Habrá en cada provincia cuerpos de milicias nacionales, compuestos de los habitantes de cada una de ellas." "La fuerza pública se compone de ejército, milicia nacional y armada." La Constitución de 1834 reprodujo en su Art. $138^{\circ}$ la fórmula del Art. $146^{\circ}$ de la carta precedente.

La segunda y tercera etapas empiezan con la Constitución de 1839, promulgada por Gamarra, en que la milicia es primero ignorada al disponer la organización de la defensa nacional en su Art. $145^{\circ}$, "La fuerza pública se compone del ejército, armaday guardia nacional." Y luego, suprimirla expresamente en su Art. 149': "La milicia deja de ser fuerza componente de la defensa nacional para ser ubicada con la policia". "La guardia nacional se compone de los cuerpos cívicos organizados."

Durante la presidencia de Castilla, en tres documentos sucesivos se introducirá un sentido nuevo al papel de la milicia, la policía y la fuerza armada. El Estatuto Provisorio de 1855, lo redujo todo a un lenguaje neutro al decir en el Art. $22^{\circ}$, "Están obligados los peruanos a concurrir al servicio de las armas en sostén del Estado, conforme a la ley de la conscripción." En la Constitución de 1856 se dispuso en el Art. 118: "El objeto de la fuerza pública es garantizar los derechos de la nación en el exterior, y asegurar el orden y ejecución de las leves." Y, por primera vez, en lo tocante a la supremacía civil, en fórmula igualmente neutra, "La obediencia militar será subordinada a la Constitución y a las leves." Para finalmente dar paso a la profesionalización del ejército, al disponer: "Art. 119, La fuerza pública se compone de las guardias nacionales, del ejército y armada, bajo la organización que designe la ley". "Toda colocación en la fuerza pública es cargo público."

Nótese que la expresión fuerza pública en las constituciones de 1826 (Art. 136) y de 1828 (Art. 146), incluía a la milicia civica; entonces, cuando al final del artículo antes glosado se dispone: "Toda colocación en la fuerza pública es cargo público." Ya se excluye a la milicia cívica como componente de la fuerza pública, la misma que quedará compuesta exclusivamente por gente profesionalmente organizada y armada.

Pero la supresión expresa de la milicia cívica vino con la Constitución de 1860, que bajo el epígrafe Garantías Constitucionales, Titulo III, dispuso en su Art. 10", "Son nulos los actos de los que usurpan funciones públicas y los empleos conferidos sin los requisitos designados por la constitución y las leyes." Clara alusión a la milicia que nunca constituyó un empleo, pero sí defensa espontánea y heroica de la Nación.

Fue en esta situación de dependencia exclusiva del ejército y armada profesionales que nos sorprendió la invasión chilena, con el resultado del fácil aniquilamiento de nuestras primeras líneas defensivas, en el Alto de la Alianza, San Francisco y Tarapacá, con el sacrificio y el heroísmo de algunos pocos jefes militares como el del comandante cusqueño Ladislao Espinar y los batallones civiles de artesanos luchando junto al ejército profesional mal preparado y pésimamente apertrechado y el holocausto del Morro de Arica. La defensa sacrificada y heroica se produjo sólo a partir del Morro de Arica por acción notable de elementos civiles, entre ellos, Alfonso Ugarte Bernal recién alistado para la ocasión y el mismo coronel Francisco Bolognesi, quien de comerciante exitoso había sido incorporado a la Guardia Nacional que en 1853 se formó en Arequipa, con motivo del litigio que había surgido con Bolivia, y entró al ejército profesional en 1854 al producirse la sublevación de aquella ciudad contra Echenique.

Rememora Basadre:

"Las campañas del sur fueron campañas del ejército profesional peruano, pero Arica simboliza el comienzo en el predominio de las milicias urbanas. De esos jefes (que juraron la defensa hasta quemar el último cartucho) no todos eran militares; algunos eran civiles, con grados episódicos y había hasta marinos sin barco [...]" (1980: p. 170, t.VI)

La ulterior línea de resistencia en Miraflores estuvo comandada y compuesta casi exclusivamente por civiles (Basadre, 1989: 208, t.VI), pues el ejército profesional diezmado y lo que quedaba de él, desorganizado y rezagado ante el impetuoso avance chileno, ya no representaba ninguna defensa.

"[...]en el curso de un mes fue formado el ejército que iba a defender Lima en Miraflores, compuesto de diez divisiones y treinta batallones [...] General en Jefe del Ejército fue nombrado el Prefecto de Lima Juan Martín Echenique y como Jefe de Estado Mayor fue designado el hacendado de Lima Julio Tenaud: Los empleados del Poder Judicial formaban la primera división, en la que habían hasta vocales supremos, bajo el mando de José Unanue, la segunda división, tenía 
como jefe a Pedro Correa, antiguo miembro de la Beneficencia y comprendía todo el ramo de instrucción pública desde los maestros de escuela hasta los catedráticos universitarios... Sergio Orbegoso, hermano de uno de los secretarios del dictador, mandaba la tercera división cuyo personal pertenecía a la alta, mediana y baja finanza. La Cuarta División compuesta del ramo de edificadores desde albaniles hasta arquitectos, hallábase a cargo de Juan de Aliaga [...] la Décima bajo Antonio Bentín, se componia, de los empleados del ferrocarril de La Oroya [...]"

Barrida también esta última línea de resistencia, final del holocausto nacional e inicio de la cruenta como latrocínica ocupación chilena, fueron las montoneras, tropas cívicas espontáneas comandadas por Andrés Avelino Cáceres las que restauraron la dignidad nacional con su larga y sacrificada resistencia en el Sur, Centro y Norte del territorio nacional; resistencia que no cejó hasta la retirada total de las tropas chilenas, en agosto de 1884 .

No obstante esa dolorosa experiencia, la Constitución de 1933, promulgada por el autócrata Luis M. Sánchez Cerro, (momentáneamente satisfecha la ambición chilena con la cesión de las provincias de Tarapacá y de Arica conforme al Tratado de 1924, igualmente más preocupado por mantenerse en el poder que por establecer las bases de la Defensa Nacional), por primera vez en las historia constitucional peruana redujo el rol de de las fuerzas armadas a las de policía, al disponer en el Art. 213": "La finalidad de la fuerza armada es asegurar los derechos de la república, el cumplimiento de la Constitución y las leyes y la conservación del orden público."

Fue bajo esta Constitución que nos rigió por más de medio siglo, cuando la conciencia cívica nacional se adormeció, hasta aceptar como natural el rol represivo otorgado al ejército $y$, de paso, olvidar el compromiso de la civilidad con la defensa nacional y la falsa idea de que de ella se debe ocupar sólo el ejército profesional.

La Constitución de 1979 introdujo el concepto de la Defensa Nacional Integral a la vez que exclusivamente profesional, al disponer en su Art. 169", "La defensa nacional es permanente e integral"; Art. 170", "Toda persona natural o jurídica está obligada a participar en ella, de conformidad con la ley." Pero, contradictoria y gravemente implicante al disponer en el Art. 174": "Las fuerzas armadas están constituidas por el ejército, la marina de guerra y la fuerza aérea. Tienen como finalidad primordial garantizar la independencia, soberanía e integridad territorial de la República, asumen el control del orden interno, de conformidad con el Art. 231"."

Fue esa Constitución, reputada, para muchos moderna y progresista, pero redactada por constituyentes con la conciencia cívica adormecida y acostumbrada al predominio militarista, la que consagró el papel represor de las FF.AA. con olímpico olvido de la civilidad en su deber con la defensa nacional. $Y$ aunque algunas de esas disposiciones fueron modificadas mediante la Ley $\mathrm{N}^{\circ} 24949$, sólo para unificar los cuerpos especializados de la policía en la "Policía Nacional" dependiente de una sola Dirección General, la misma Ley creó el Ministerio de Defensa y con él, las Comandancias Generales de las tres armas, venciendo el reparo que se había expresado en el Art. $122^{\circ}$ de la Constitución de $1856 .^{\dagger}$ En cambio, no mejoró nuestra capacidad defensiva y de movilización social ante las potenciales amenazas externas, como lo hace notar el constitucionalista Alfredo Quispe Correa (1994: 107) "[...]poco es lo que podemos encontrar en las diversas constituciones que ha tenido el pais, para las cuales la guerra se reduce al enfrentamiento armado, la planificación les es desconocida, el. proyecto nacional no existe por la heterogeneidad de los intereses en pugna, que hacen aun de nuestro pais un archipiélago y no una empresa colectiva, y la defensa nacional sinónimo de guerra."

La Constitución de 1993, engendro del régimen fujimorista, si bien en su Art. $163^{\circ}$ introduce el concepto de "Defensa Integral", remplazó en cambio el concepto del deber por el de obligación y dispersó aun más su marco normativo, bajo disímiles epígrafes (véanse los artículos $38^{\circ}$, $44^{\circ}, 163^{\circ}$ y $167^{\circ}$, por ejemplo) que además de inconexos, son contradictorios porque, primero, hacen recaer en todos los peruanos el deber de honrar y proteger los intereses nacionales (Art. $38^{\circ}$ ), -entre ellos, es de suponer, la soberanía y la defensa de la Nación- para luego convertir al Estado en "protector de la población de las amenazas externas" (Art. 44\%); sin considerar que pueblo y Estado constituyen una unidad política, jurídica, conceptual e institucional.

Con la secular carencia de un Sistema de Defensa Nacional, la marginación deliberada en el Perú de la civilidad de esa tarea -civilidad a la que 
se llamará sólo ante la necesidad de la morilización nacional-, pero aún sin que esté preparada para la lucha, se debe en gran medida el divorcio actual entre el militar de carrera ( $\mathrm{y}$ aun del simple recluta) y el civil. No obstante la idea diferente de Tocqueville (1957: 599) $)^{5}$, seguramente fruto de otras realidades y experiencias:

"Los simples soldados son los que permanecen siempre como ciudadanos en el ejército de los pueblos democráticos, y sobre ellos conservan gran poder e influencia los hábitos y opiniones nacionales; de manera que ésta es la clase por donde se puede con más facilidad hacer penetrar en el seno de un ejército democrático el amor a sabido inspirar al pueblo mismo..."

Ese divorcio que ya es parte de nuestra cultura, ha creado la idea de que los ejercicios militares sólo atañen a los elementos uniformados; convirtiendo así en fórmula declarativa "los deberes para con la patria", expresados en el Art. $38^{\circ}$ de la Constitución vigente.

De paso, casi imperceptiblemente, como hemos señalado, se ha borrado la línea maestra y fundamento esencial del constitucionalismo occidental, entre las funciones de las fuerzas armadas -destinadas a la defensa exterior-y las funciones de las fuerzas policiales -consagradas a velar por la seguridad de las personas y bienes, y el orden interno. Es así cómo muchas de las aventuras golpistas de los últimos tiempos en el Perú han estado abiertamente secundadas por la policía; y ésta, de garante de la seguridad ciudadana, ha pasado a ser fuerza neutra, en fuerza deliberante $y$ hasta beligerante en el plano político ${ }^{6}$.

La policía además está siendo sustituida por cuerpos municipales, como los serenos, en lo que deberían ser sus funciones propias, y aun por fuerzas de organización privada como los policias de seguridad. Esta policía de seguridad que obedece a reglamentos y mandos privados emplea a elementos de franco o de vacaciones de la Policía Nacional, uniformada y armada por el Estado, basado en sus reglamentos y en convenios administrativos, con el pretexto de mantener un nivel remunerativo mínimo a su favor. Zaffaroni

(2000: 17) ha advertido con sentimientos de alarma ese cambio:

"Con los cambios en el poder mundial, la llamada ideología de seguridad nacional ha sido archivada, pero está siendo reemplazada por un discurso público de seguridad ciudadana como ideología (...) La imagen bélica del poder punitivo tiene por efecto: a) Incentivar el antagonismo entre los sectores subordinados de la sociedad; b) Impedir o dificultar la coalición o el acuerdo en el interior de esos sectores; c) aumentar la distancia y la incomunicación entre las diversas clases sociales; d) potenciar los miedos (espacios paranoicos), las desconfianzas y los prejuicios; e) evaluar las actitudes y discursos por la vida y la dignidad humanas; 'f dificultar las tentativas de hallar caminos alternativos de solución de conflictos; g) desacreditar los discursos limitadores de la violencia; $h$ ) proyectar a los críticos de los abusos del poder como aliados o emisarios de los delincuentes, e i) habilitar la misma violencia respecto de aquéllos".

Recientemente, con motivo de la reinstitucionalización nacional post Fujimori, los militares han hablado de un Libro Blanco de la Defensa Nacional iniciativa del Ministerio de Defensa del Perú, donde se dice:

"El Libro Blanco [...] es la explicitación de la política de defensa de un país. En él se señala con transparencia qué política de defensa se tiene y qué medios se piensa utilizar para alcanzarla. Uno de estos medios es la Fuerza Armada. [...] Asimismo, se pone de manifiesto su organización y su despliegue.

[...]

"En la medida de que esto es materia de un acuerdo social, el Libro Blanco legitima tanto la política de seguridad y defensa nacional como a la propia Fuerza Armada, ya que ésta no es una creación voluntariosa o una imposición del Estado, sino el resultado de una profunda necesidad y anhelo de la propia sociedad..." (libroblanco@mindef.gob.pe)

Según el índice ${ }^{7}$ inserto en la página, el Libro Blanco concentra en la Fuerza Armada, una vez más, toda la idea de defensa nacional; no hay la más mínima mención a la milicia cívica u otras formas

5. Rafael Bielsa (1957:231), refirićndose a la naturaleza civil del poder de policía, dice: "En el Fstado de Derecho, la policía es organización civil y no militar[...]. Por consiguiente todo procedimiento drástico, y todo empleo de medios no proporcionales a la necesidad es anómalo y puede originar responsabilidad y recursos jurisdiccionales."

6. Que es lo único que se ha publicado, porque el contenido será resultado de los debates.

7. El libro de Naranjo Mesa contiene el cuadro pormenorizado de los regímenes militares que se dieron en Iberoamérica en las tres última décadas, el modo cómo empezaron y terminaron, incluidos los caracterizados como "cívico-militares". 
de organización social, salvo que el Capítulo VIII. Medios no militares para la defensa nacional, lo incluya, sin que podamos comprobarlo.

Para terminar este tema, conviene recordar las palabras premonitorias de Jorge Basadre (pág.173), escritas como corolario de su relato de La Guerra con Chile:

"Bolognesi y los suyos probaron que ni los ejércitos, ni los pueblos, ni los hombres, deben fijarse exclusivamente en la utilidad inmediata o en las consecuencias visibles de sus grandes decisiones. El que muere, si muere donde debe, vence y sirve. La astuta prudencia saca con reparos perezosas excusas para la tibieza transitoria, la inactividad y el egoísmo".

\section{El Militarismo GOMO FUENTE DEL PODER DE FACTO}

Louis Smith (1995: 19), en su documentado estudio de La Democracia y el Poder Militar en los EE.UU. de Norteamérica reafirma que uno de los viejos y difíciles problemas de la sociedad política es el de la apropiada relación entre el poder militar y la autoridad civil:

"Desde lo primitivos escritos sobre filosofia políica hasta los actuales debates en el Congreso Norteamericano o en el Consejo de Seguridad de las Naciones Unidas, es éste un tema recurrente. Pero mucho más que una discusión académica incesante, es un problema tan antiguo como la misma civilización; por tanto, fundamental en el arte de gobernar, de cuya solución afortunada dependerá el bienestar del pueblo y la supervivencia del Estado".

A este propósito, los constituyentes peruanos de 1993 pusieron en los artículos $167^{\circ}$ y 169", "La Fuerzas Armadas y la Policía Nacional no son deliberantes." "Están subordinadas al poder constitucional". Fórmula inocua que, como ya señalamos, empezó con la Constitución de 1856. Pues, la alusión al Poder Constitucional en una sociedad con elevada mentalidad militarista es inocua y la jefatura suprema del presidente puede ser entendida en tiempo de paz como complicidad a la hora de reprimir a la población civil, como más de un presidente ha hecho en sus veleidades por el poder. Hace falta una norma escueta y suficiente que diga: "Las Fuerzas Armadas están subordinadas al poder civil', y basta.

Smith (p.23), informa sobre el mínimum constitucional, con que el tema militar debe ser tratado:

"El constitucionalismo occidental ha construido paulatinamente un sistema de carácter legal $\mathrm{y}$ administrativo destinado al mantenimiento del control civil, que comprende: establecer expresamente en la Constitución Política el principio de la supremacía del poder civil sobre el poder militar; la limitación específica de los fines y forma de empleo de las armas militares; obligar a todo el personal de oficiales a prestar juramento a la Constitución, y haciendo del cuerpo legislativo nacional la sola fuente de autoridad para todas las reglamentaciones sobre la disciplina interna del servicio armado, con la disposición anexa que diga que tal autoridad disciplinaria se vuelve inoperante a menos que sea renovada la legislatura. Además de otras como la exigencia de una rendición final de cuentas."

\section{LOS REGÍMENES MILITARES LATINOAMERICANOS DE LAS ÚLTIMAS DÉCADAS}

En la opinión documentada de Naranjo $(2000,629-638)^{7}$ :

"[...] los regímenes autocráticos tradicionalistas más característicos del mundo contemporáneo son, tal vez, las dictaduras militares de América Latina. Casi desde el inicio mismo de su vida independiente, la mayoría de los países latinoamericanos ha tenido que soportar esta clase de regímenes, que no en pocos casos ha revestido la forma de verdaderos totalitarismos."

En esos treinta años, según el recuento de Naranjo: Argentina ha soportado quince dictaduras militares, Bolivia dieciocho, Brasil veintiuno, Chile dieciséis, Ecuador ocho, Honduras quince, Panamá veintiuno, Perú trece, y Uruguay doce; en tanto que Haití y Paraguay, apenas en los últimos años han logrado salir de él. Otros dos, Cuba y Nicaragua pasaron directamente de prolongadas dictaduras personalistas de tipo tradicional, a dictaduras de tipo socialista-marxista. El Salvador y Guatemala, por su parte, han vivido este lapso sucesivos golpes de Estado, dictaduras militares y gobiernos provisionales, prolongándose en ellos la inestabilidad institucional que ha sido característica en la historia de Centroamérica. En algunos casos como los de Panamá entre (1969 y 1989), República Dominicana (entre 1960 y 1978) y Uruguay (entre 1973 y 1985), los militares han ejercido de hecho el poder a través de mandatarios civiles impuestos por ellos. En otros como en el de Paraguay, lo han ejercido a nombre de un partido monopólico oficialista. Solamente Colombia, Costa Rica, México y Venezuela no experimentaron golpes ni dictaduras militares durante este período de la historia contemporánea. 


\section{LA POLITIZACión DEL MILITAR PERUANO}

Villanueva, (1971: 187) dice:

“...la legitimidad que el militar (peruano) considera poseer para gobernar proviene de la forma pacífica, sin resistencia alguna, con que tomó el poder al proclamarse la república. Fue tan natural esa adhesión que el militar llegó a considerar como legítimo su derecho a gobernar, concepto que se arraigó con el ejercicio cincuentenario del gobierno". Añade, que más tarde fueron los propios civiles quienes dieron el espaldarazo a los militares sobre esa legitimidad por boca de Manuel Pardo quien, en 1876 elogió: "el principio democrático en la alternabilidad del poder.”

Desde el inicio de su vida independiente, y hasta antes de la Guerra con Chile, casi sin interrupción, gobernaron el Perú, los siguientes caudillos militares: Mariscal José de la Mar, 18271829; general Agustín Gamarra, 1829-1833; general Luis José Orbegoso 1833-1835; general Felipe S. Salaverry, 1835-1836; mariscal Andrés de Santa Cruz, 1836-1839; mariscal Agustín Gamarra, 1839-1841, murió en la Batalla de Ingavi; general Manuel Menéndez, 1841-1842; general Juan C. Torrico, 1842; general Francisco Vidal, 1842-1843; general Justo Figuerola, 1843 (encargado de la Presidencia); general Manuel Ignacio de Vivanco,1843-1844; general Ramón Castilla, 1845-1851; general José Rufino Echenique, 1851-1855; general Ramón Castilla, 1855-1852; general, Miguel de San Román, 18621863; general Juan Antonio Pezet, 1863-1865; general Mariano I. Prado, 1865-1868; Coronel, José Balta, 1868-1872.

En el siglo XX, los gobiernos de facto fueron reiniciados, esta vez de signo claramente golpista en 1930 por el entonces general Augusto Bernardino Leguía, quien consiguió gobernar dos períodos constitucionales hasta 1930, año de su final trágico, porque como nunca, pasar transitó casi directamente del palacio de gobierno a la cárcel pública. El breve interregno constitucional del jurista Luis Bustamante Rivero fue interrumpido por el golpe de Estado dirigido desde Arequipa por el comandante Luis M. Sánchez Cerro (19301933), el gobierno civil que siguió fue también interrumpido por el general Oscar Raimundo Benavides (1933-1939); otro general, Manuel A. Odría usurpó el poder entre 1948-1956, el gobierno civil que siguió fue depuesto por una Junta militar 1962 que gobernó hasta 1963. El gobierno del carismático Fernando Belaunde
Terry fue interrumpido por la junta militar presidida por el general Juan Velasco Alvarado (1968-1975); un contragolpe al interior de la Junta colocó en la presidencia al general Francisco Morales Bermúdez (1975 y 1980), durante el cual se discutió y promulgó la Constitución de 1979. El retraso material y cultural, el deterioro del espíritu cívico-moral, las corruptelas y negociados, el forado presupuestal, el enriquecimiento de unos pocos, el debilitamiento de la clase media, el envilecimiento de las costumbres sociales, se debe siempre a esos regímenes de facto.

Para los propósitos de este trabajo nos interesan especialmente los tres últimos períodos de interrupción democrática debido a golpes de Estado: el del primer gobierno del Arq. Fernando Belaúnde, que empezó el 3 de octubre de 1968, con su extrañamiento del país y la instalación de la dictadura del General Juan Velasco Alvarado, reemplazado en 1975 -al interior mismo del régimen militar- por el contra golpista General Morales Bermúdez y que sólo concluyó el 28 de julio de 1980 al jurar su segundo gobierno el mismo Arq. Belaúnde Terry. Fueron consumidos así más de dos períodos gubernamentales democráticos. Además, el inédito rebelión-autogolpe del 5 de abril de 1992, del entonces gobernante constitucional Alberto Fujimori contra la Constitución de 1979 y que sólo concluyó el 22 de noviembre del 2000, cuando el Congreso de la República lo vacó en ausencia por grave y permanente incapacidad. Esta interrupción le costó al Perú otros dos períodos gubernamentales que por haber nacido de un comportamiento especialmente alevoso, merecen ser analizados desde sus orígenes.

\section{LA ALIANZA PERVERSA Y EL ABATIMIENTO DE LA DIGNIDAD MILITAR}

Después de las elecciones de 1990, el recién electo presidente constitucional Alberto Fujimori, antes aún de ocupar su despacho presidencial, se trasladó a una base militar donde desarrolló una estrategia secreta con Vladimiro Montesinos, hasta entonces un abogado de ejercicio privado con un vergonzoso pasado militar para purgar a las Fuerzas Armadas de posibles opositores y sentar las bases para un control más estrecho del alto mando. Al tomar el poder, el Comando Conjunto y el Alto Mando de las fuerzas policiales fueron purgados de la mayoría de sus altos oficiales. Esto fue, sin embargo, solamente el primer paso de los esfuerzos del gobierno para reestructurar las 
fuerzas de seguridad y acomodarlas a sus designios propios. Lo mismo pasó con las instituciones democráticas: Congreso, Poder Judicial, Tribunal Constitucional y los órganos autónomos de control. Todos ellos fueron intervenidos.

En lo especificamente castrense, la administración Fujimorista, caracterizada por el personalismo y la concentración del poder, tuvo un efecto devastador. Las prerrogativas institucionales desarrolladas por décadas fueron reemplazadas por una red de relaciones a nivel de cúpula, entre Fujimori, Hermoza Ríos y Montesinos y de éstos con sus allegados, en los mandos medios. La independencia institucional fue severamente recortada. Significó además que las instituciones civiles perdieran el control democrático necesario sobre las Fuerzas Armadas. Además, como era de esperarse, las tensiones y los conflictos entre estas tres poderosas personalidades generaron importantes crisis internas en las FF.AA y las fuerzas de seguridad. A la vez que socavaron la institucionalidad toda del país.

Una serie de decretos legislativos y normas internas dados por el ejecutivo entre 1991-1992, revertieron la mayoría de esas regulaciones y sentaron las bases de la desprofesionalización y politización de las Fuerzas Armadas. El General Hermoza no se encontraba en el quinto superior de la ESG y su selección, como la mayoría del alto mando desde 1991, se basó solamente en su lealtad a Fujimori y Montesinos y por el D. Leg. 752, dado en noviembre de 1991, se hizo indefinido el período del Comandante General, sólo sujeto a la confianza del Presidente. Es así que Hermoza Ríos permaneció en su posición dual de Comandante General del Ejército y Presidente del Comando Conjunto entre 1991 y 1998. Pcro a pesar del resentimiento que debió provocar entre la oficialidad, desde 1992 no se conocieron protestas ni rebeldías en el interior de las Fuerzas Armadas. El único oficial General, Rodolfo Robles, que se manifestó en contra del statu quo denunciando la existencia de escuadrones militares de la muerte fue forzado al exilio después de revelar información.

El otro factor que igualmente minó la institucionalidad castrense y debilitó su autoestima fue su involucramiento en el narcotráfico que, según el estudio de Ricardo Soberón Garrido ${ }^{8}$, se debió a que desde 1984 tanto Sendero Luminoso como el MRTA, eligieron asentarse política y militarmente en las regiones cocaleras de los departamentos de Huánuco y San Martín, respectivamente. Este factor coadyuvó a que dentro del Estado y la opinión pública peruana se justificara el ingreso de las FF.AA en los valles cocaleros.

\section{RÉQUIEM DEL RÉGIMEN FUJIMORISTA}

Sin embargo, no fueron aquellos excesos los que deslegitimaron al fujimorismo sobre todo ante los organismos internacionales democráticos, sino la pretensión reeleccionista de Fujimori, violando los mandatos del Sistema Democrático de la Carta Americana. Fue entonces, que la OEA estableció en Lima, en julio del 2002, una Mesa de Diálogo donde:

"...representantes del gobierno, oposición y sociedad civil debían debatir sobre el fortalecimiento democrático, la reforma del sistema judicial, del sistema electoral, la reforma del aparato militar y la restitución de los medios de comunicación a sus legítimos propietarios."

Esta decisión se tradujo, en el ámbito interno, en un acuerdo político para reformar la Constitución, que el gobierno quiso condicionarlo a la aprobación por el Congreso de una amnistía a los militares implicados en procesos judiciales por narcotráfico. Los implicados en las matanzas ya habían sido amnistiados. En consecuencia, el 5 de noviembre del 2000 entró en vigencia la Ley N $^{*} 27365$, la tercera reforma de la Constitución de 1993, con el fin de que el tercer mandato del aún presidente y de los congresistas culminara en julio del 2001.

Cuando la crisis llegó a su punto de no retorno, Fujimori buscó alejarse del país, saliendo entonces rumbo a Brunei, con el pretexto de participar en una conferencia internacional sobre la Economía Asia-Pacífico, pero siguió de largo hasta Japón desde donde envío por fax su renuncia. El 22 de noviembre del 2000 el Congreso declaró la vacancia presidencial de Alberto Fujimori por causa de permanente incapacidad moral; el cambio de postura del oficialismo congresal que entonces votó con la oposición se debió al "video KouriMontesinos".

Una crónica de esos días en el diario Liberación, (Lima abril 16-2001, pág. 3), habla del modo humillante como los aliados militares del régimen, volvieron a sus cuarteles: 
"A través de un mensaje a la Nación el presidente del Comando Conjunto de las FF.AA. y Comandante General de la Fuerza Aérea del Perú, Pablo Carbone Merino, anunciará hoy que los comandantes generales de las tres armas y el director general de la Policía han puesto sus cargos a disposición. En el mensaje grabado Carbone aborda tres puntos: el primero de ellos expresar el respaldo total de cada uno de los jefes militares, a la Constitución y al Gobierno Constitucional del presidente Paniagua. En segundo lugar, los tres comandantes y el director de la Policía Nacional se retractan del indigno compromiso que asumieron al firmar en 1999 el acta de sujeción a la banda delincuencial que gobernaba el país. En tercer lugar, Carbone, Tafur, Ramos y Santisteban ponen sus cargos a disposición del presidente de la República para que éste disponga lo conveniente [...]"

\section{RECELOS EN LAS RELACIONES GÍvICO- MILITARES}

Nicolás Maquiavelo escribió con profundo realismo, el pensamiento copiado como epígrafe al inicio de este artículo. Denotando que esta experiencia es universal, además de actual, dice Alexis Tocqueville (1963, 71-72):

"Cuando el espíritu militar abandona a un pueblo, la carrera militar deja de ser también estimada y los hombres de guerra bajan al último puesto de los funcionarios públicos; se les aprecia poco y no se les atiende. Entonces sucede lo contrario de lo que se da en los siglos aristocráticos: no son los principales ciudadanos los que entran al ejército, sino los menos importantes. [...] Lo más selecto de la nación huye de la carrera de armas, porque no es honrosa [...] El soldado se siente en una posición inferior y su orgullo herido acaba por darle el gusto de la guerra o el amor a las revoluciones, durante las cuales espera conquistar con las armas en la mano la influencia política y la consideración individual que se le disputa."

En el Perú, la mutua desconfianza y hasta aversión entre civiles y militares viene de la época en que la empresa conjunta de la independencia nacional concluyó y como vimos (supra 3), el papel ordenador de las primeras constituciones señaló roles específicos a los ejércitos; y aún más, previno para que el militarismo no se convirtiera en casta con ínfulas de superioridad y designios de casta gobernante.

Los constituyentes franceses de 1793, entre otras normas a este propósito, dejaron establecido en el Art. $111^{\circ}$ del Acta Constitucional "La diferencia de grados, sus signos distintivos y la subordinación sólo subsisten en relación al servicio y mientras éste dure."

Pero en el Perú y seguramente en otros países de tradición militarista, los militares retirados no dejan de ostentar sus signos distintivos y sus prerrogativas; disfrutan junto con su pensión en dinero, de provisiones y servicios gratuitos que su institución incluye en la resolución de su cese y que los perciben efectivamente por estar presupuestados; adicionalmente, y con carácter general, las leyes presupuestales consignan asignaciones específicas a favor de las asociaciones de retirados; a ello se debe los presupuestos siempre elevados de las Fuerzas Armadas y Policiales, dado que ambas instituciones están homologadas por la Constitución, pues, conforme al Art. 174", "Los grados y honores, las remuneraciones y pensiones inherentes a la jerarquia de oficiales de las Fuerzas Armadas y de la Policía Nacional son equivalentes..."Y si además prestan su apoyo al sostenimiento de algún autócrata, esas ventajas se multiplican. Por otro lado, la oficialidad mantiene asociaciones de retirados que los gobiernos favorecen invirtiendo en sus infraestructuras y equipamiento; auspiciando en buena cuenta los cenáculos militares en los que la mentalidad de casta se mantiene y aún profundiza.

Algunos de esos privilegios se instituyeron en épocas en que los pueblos y, a su turno los Estados, debieron reconocer servicios excepcionales a los militares, sea en la defensa o en la guerra que en nuestra época son cada vez más episódicas. Esa acendrada tradición ha impedido reflexionar y aún educar que la persona incorporada a la vida militar lo hace temporalmente: es civil antes de ser militar y vuelve a ser civil después de ser militar. Es más, muchos militares retirados buscan postular a cargos públicos; entonces recién estiman su condición civil y buscan el respaldo del electorado.

La mencionada Acta de la Constitución Francesa dispuso, asimismo, en su artículo $110^{\circ}$, "No hay ningún generalisimo". El Perú no reconoce el rango de generalísimo, pero muchos oficiales aspiraron a detentarlo, como una exigencia a la Nación por algún logro, legítimo o superlativizado. Así lo pretendió el General Benavides y últimamente lo ambicionó el General Hermoza Ríos el autoproclamado general victorioso por el conato de guerra en el Cenepa, con el cual lucró antes que peleó; sin pensar que esa ambición le atraería los celos del autócrata y su asesor Montesinos, 
causando su final perdición en el delicado y celoso equilibrio del poder. ${ }^{9}$

Víctor Villanueva $(1971,165)$ afirma:

"Empero sucede que los profesionales de la guerra proclaman su aversión a la política en general y rechazo a la práctica política, siendo así que siempre pensaron en términos políticos e históricamente actuaron políticamente cada vez que se presentó una coyuntura. Esta manifiesta contradicción parece, pues, ser más aparente que real."

Y con su experiencia de capitán retirado del Ejército peruano, añade:

"El sentimiento de casta del oficial peruano ha sido fortalecido durante toda su existencia por una serie de mecanismos. El agachamiento de las instituciones civiles[...] el aislamiento social en que vive y que le hace pensar que el cuartel es su mundo; el desprecio por el civil que se inyecta al soldado desde que ingresa al servicio; [...]el ejercicio de la violencia (institucionalizada) cuyo monopolio posee; los beneficios económicos que le permiten sortear las épocas de crisis; el status institucional, y en fin, el hecho de pertenecer a una "institución tutelar de la patria"; conducen al militar a identificar sus propios intereses con los de la Nación [...]"

Con otras palabras, pero lo mismo, dice Alexis Tocqueville (1957: 556):

"Lo que aumenta [...] el espíritu militar y turbulento del ejército[...] es el carácter pacífico de los ciudadanos; nada hay más peligroso que un ejército en el seno de una nación que no es guerrera; el amor excesivo de todos los ciudadanos por la tranquilidad pone diariamente la Constitución a merced de los soldados."

La sorprendente transformación mental del militar cuando emprende la represión o una aventura golpista ha sido recreada por Isabel Allende (2000: 50), con ocasión del derrocamiento del presidente Salvador Allende, patentizando el cambio violento que sufre su personalidad:

"[...]en cada peldaño de la amplia escalera de piedra había soldados apostados, parecían haber enloquecido, pateaban y golpeaban con las culatas a los que bajaban con un odio nuevo recientemente inventado, que había florecido en ellos en pocas horas, algunos disparan sus armas por encima de las cabezas de los rendidos[...] Siguieron golpeándolos hasta la calle y allí les ordenaron acostarse boca abajo en el suelo, les pisaron, les insultaron hasta que se les acabaron las palabrotas del castellano y entonces le hicieron señas a un tanque. Los prisioneros lo oyeron acercarse estremeciendo el asfalto con su peso de paquidermo invencible jabran paso que los vamos a pasar por encima a estos huevones! gritó un coronel[...]"

Nos hemos preguntado siempre, sin hallar respuesta razonable ¿dónde y cuándo se acuñó ese título de institución tutelar que suele darse en documentos y ceremonias oficiales a las FF.AA y que últimamente hasta las fuerzas policiales lo reclaman como su emblema? Para un jurista, la tutela se ejerce sobre personas incapaces. Pero, si alguna Constitución o ley ordinaria proclamó exprofeso alguna vez ese tutelaje y pronto quedó borrado por impertinente o anacrónico, fue de algún modo renovado por la Constitución de 1993, al decir en su Art. $166^{\circ}$, "La Policía Nacional, presta protección y ayuda a las personas." Cuando debiera decir: "garantiza su seguridady la de sus bienes". Y en su Art. $44^{\circ}$, al decir, "Son deberes primordiales del Estado, defender la soberania nacional... proteger a la población de las amenazas contra su seguridad." Y como quiera que el Estado -persona moral- no tiene capacidad propia para ejecutar esa tarea, al ejecutarla en su nombre, ¿las FEAA, realizan una función tutelar?

En fin, a los peruanos -pueblo pacífico, sin duda-nos han educado con el fetiche del uniforme y la superioridad militar, porque casi dos tercios del tiempo de la vida republicana consentimos gobiernos militares, sin insurreccionar.

Incluso Andrés Avelino Cáceres, (Basadre, 304: t. VII) que, sacrificando familia y hacienda propias, fue nervio y cerebro de la epopeya que forzó la retirada del ejército invasor y como ninguno supo dar cumplida cuenta de los gastos de la campaña a cargo del erario, gastos increíblemente escasos para tremenda epopeya ${ }^{10}$, también se dejó seducir por el poder. Después de

9. El General Hermoza Ríos ha volcado esas experiencias en un voluminoso texto que ha titulado: "Fuerzas Armadas del Perú, Lecciones de este Siglo, homenaje a los soldados[... ]" Pero hoy sufre prisión común al habérsele descubierto cuentas secretas personales y familiares en Suiza por más de siete millones de dólares, sobre cuyo origen ha tenido que aceptar proviene de comisiones por la compra de armas para aquella guerra apenas anunciada, librándose así de la imputación más grave y deshonrosa de narcotráfico.

10. Los documentos presentados para su examen al Tribunal Mayor de Cuentas por el Jefe de la Sección de Contabilidad del Ejército del Centro y Comisario de Guerra acreditan que las campañas de resistencia desde el 27 de abril de 1881 hasta el 31 de diciembre de 1883 sólo costaron a la Nación S/.396,660.03. 
ser Presidente Constitucional, aunque consiguió la reelección en 1984 en elecciones limpias pero luctuosas, tuvo que dejarla cuando el delegado apostólico José Macchi le dijo: "General, a Ud. (ahora) lo odian hasta las piedras, no vale que derrame más sangre, aunque venza no podrá ya Ud. gobernar".

Debemos recordar que después de la Guerra de Independencia y de la Guerra con Chile, el valor, el heroísmo, y la honradez del militar peruano se han tornado episódicos o singulares, en tanto que su desprestigio ha crecido al mismo ritmo de su afán por la captura del poder y los privilegios. Por otro lado, una reglamentación militar poco sopesada hasta ahora nos ha sumido en la apatía al no dejarnos ver que el ejército es débil en la guerra, porque el derecho de antigüedad sigue siendo ley suprema en los ascensos, sobre la desventaja estratégica que ello conlleva. A este propósito, Alexis Tocqueville (1957: 603) dice:

"Resulta pues que cuando, después de un largo reposo, toma un pueblo democrático al fin las armas, todos los jefes del ejército son ya viejos. [...] Si se examina un ejército democrático después de una larga paz, se ve con sorpresa que todos los soldados son jóvenes, mientras que los jefes declinan; de suerte que a los primeros les falta la experiencia y a los otros el vigor".

$\mathrm{Si}$ los peruanos, civiles y militares, quisiéramos cambiar este afrentoso escenario, buscando enfrentar mejor las amenazas externas $\mathrm{y}$ aún internas, siempre latentes en nuestro horizonte, deberíamos emprender una cultura de relaciones mutuamente respetuosas, hermanadas y coadyuvantes, por la única causa que es esta nuestra Nación y nuestra Patria. Si no actuamos con ese propósito de enmienda, la repulsa de Albert Einstein (1984: 119) al falso patrioterismo de que disfraza la clase militar sus propias carencias y frustraciones, cobrará vigencia:

"Mi ideal político es la democracia. Que se respete a cada hombre como individuo y que no se convierta a ninguno de ellos en ídolo[...]" "Ese tema me lleva al peor producto de la vida de rebaño, el sistema militar el cual, detesto[...] Esta plaga de la civilización debería abolirse lo más rápidamente posible. Ese culto al héroe, esa violencia insensata y todo ese repugnante que se conoce con el nombre de patriotismo. Con que pasión los odio, qué vil y despreciable me parece la guerra[...]"

\section{Nuestras Relaciones Gon Chile}

Como nota final, es indispensable referirnos a nuestras relaciones con Chile que por profesión, nuestra clase militar y por reflejo la población en vigilia tienen muy presente como la amenaza chilena, innegablemente subsistente, no obstante la firma de los Acuerdos de Lima que Fujimori presentó como la feliz culminación de un proceso de distensión, a semejanza de la aún discutida paz lograda con Ecuador. Lo real es que aún mantenemos significativos conflictos de intereses actuales con dicho país derivados de los tratados que pusieron término jurídico a la Guerra del Pacífico. Uno de ellos es la demarcación marítima pendiente que se extiende mar adentro desde la Línea de La Concordia que hace nuestra frontera con Chile, porque el acuerdo de 1952 contiene un error lesivo para el Perú al haberse fijado el mar territorial conjuntamente con Chile y Ecuador paralela a la franja costera peruana de líneas muy sinuosas, en tanto que Chile tiene una franja uniforme. Conflicto cuya existencia Chile niega en todos los canales de nuestras relaciones y maneja eficazmente su prensa, como el artículo en Internet de Oscar Mertz ${ }^{11}$, bajo el título: Nuestras relaciones con el Perú del 17 de febrero del 2002, con ocasión de la visita del Presidente Alejandro Toledo a Chile ofreciendo el desarme unilateral del Perú:

"Chile es un país que ha aceptado el curso actual de sus fronteras, no aspira a anexar territorios limítrofes y, en consecuencia, su política de defensa responde a la necesidad de defender el statu quo con un sistema militar dotado de capacidad meramente disuasiva. Sin embargo, no es posible encontrar en el ambiente vecinal la misma disposición a respetar estas fronteras, primando más bien aspiraciones oceánicas, bioceánicas e irredentismos territoriales que conducen a una concepción de las respectivas Fuerzas Armadas con capacidades que van más allá de la disuasión."

Hay que reconocer que nuestra diplomacia enfrenta escollos formidables. Persiste en Lima un sentimiento antichileno, como lo demuestra una encuesta publicada por el diario La Tercera en agosto del 2005, según la cual, el 60\% de los entrevistados tiene una visión desfavorable de los empresarios chilenos y un $65 \%$ estima que la relación con Chile es sólo regular, frente a un magro $21 \%$ que piensa que es buena. Conociendo estos

11. Página web:w.udp.ci/comunicaciones periodismo/t2004/jara.pdf 
sentimientos, los políticos peruanos suelen recurrir al refrescamiento de los mismos, aunque sólo para aumentar su votación o para sobreponerse a las valoraciones negativas de su desempeño que esas mismas encuestas muestran. Sin embargo, no deja de sorprender que el Presidente Toledo utilizara esos mismos recursos cuando durante su candidatura buscó la amistad chilena y, en particular, la del Presidente Lagos. Pese a ello, ya en marzo pasado el entonces candidato a la presidencia Alejandro Toledo llamó a no consumir productos Lucchetti a 19 días de las elecciones, y ahora suspende una visita a nuestro país, gesto que debe ser interpretado como un desaire.

Y desde la óptica académica de dos altos oficiales chilenos: $^{12}$

"En el caso de Chile, las instituciones armadas se encuentran abocadas a sus planes de modernización y renovación de material obsoleto[...] Esta fuerza se encuentra en franca modificación de su tradicional concepto de presencia territorial, buscando una estructura más flexible a través de sistemas operativos organizados a base de unidades completas, dotadas con todo lo necesario para hacerlas plenamente operacionales.

En el caso de los países latinoamericanos se considera importante la opinión que desde el año pasado los EE.UU. sostenía de los cinco países sindicados como "aliados estratégicos en la región" (Canadá, México, Brasil, Colombia y Chile). Entre éstos, indudablemente, ha destacado la relación bilateral con Chile y México derivado de su condición de integrantes del CSNU. Este aspecto se ha visto reflejado con toda su intensidad en las presiones recibidas por ambos países, con el fin de que apoyaran explícitamente la postura norteamericana en contra de Irak. [...]

En lo inmediato, en la subregión continuará privilegiándose la cooperación y los mecanismos diplomáticos para resolver las controversias, pero como se señalara anteriormente, sin descartar de plano que el uso de la fuerza pueda ser una opción necesaria frente a amenazas emergentes que pueden derivar hacia conflictos entre estados. $[\ldots]$ es necesario tener presente que, a pesar de los procesos de integración y cooperación que hoy vivimos, los diferentes actores mantienen la intención de imponer sus propios intereses, estando siempre latente la posibilidad de ocurrencia de crisis que pueden derivar en un conflicto, situación que, aunque atenuada actualmente, mantiene vigente el uso de la fuerza en legítima defensa y como último recurso del Estado Nación, tal como lo establece la Carta de las Naciones Unidas."

Una nueva confrontación con Chile siempre debemos considerarla latente, sino inminente; y para enfrentarla no sólo con suficiencia sino con ventaja, debemos prepararnos con sentido de responsabilidad, para que no vuelvan a infringirnos la humillación de 1881; para evitar nuevas pérdidas, incluso, sin pensar en recuperar lo usurpado. Los motivos de la confrontación bélica no han desaparecido, alli está el secular problema de la mediterraneidad de Bolivia, nuestra aliada ancestral y están los extensos intereses económicos chilenos en territorio peruano que sus gobiernos han prometido defender, al puro estilo y mentalidad norteamericanos; de allí también su alianza natural. Y si el destino nos llevara a esa nueva confrontación, nunca más aceptemos la mediación de la EE.UU. de Norteamérica ${ }^{13}$ porque sus intereses siempre fueron más compatibles con los de Chile que con los nuestros, como claramente piensan los oficiales chilenos que escribieron el artículo copiado. Nuestra preparación no sólo ha de consistir en modernizar el equipamiento y los pertrechos militares y capacitar al personal militar, sino introducir la milicia civil permanente, con métodos, objetivos e instrucción diferentes a lo que se llamó la instrucción premilitar, y las reservas del ejército con sus listas pasivas; a la vez que repensar en un sistema y procedimientos de reclutamiento para las listas activas, superando el sistema medieval abolido en nombre de la protección de los derechos fundamentales.

12. Los tenientes Coroneles Claudio Andaur. Urbina, Mauricio Araya Mourges, exhiben las calificaciones de Oficial de Estado Mayor, Magíster en Gestión y Planificación Estratégica de la Academia de Guerra del Ejército, Oficial Analista del CESIM, Profesor de Academia en la Cátedra de Logística, Comandante del Grupo de Observadores de Naciones Unidas en Siria, etc. (www.caer.com.ar/es).

13. Jorge Basadre ha registrado, con sentido de denuncia, la actuación parcializada del comisionado norteamericano Hurbult, en las tratativas de paz con Chile para su retiro del territorio invadido; Hurbult, condenaba en apariencia la pretensión de cesión chilena; a la vez promovía pronunciamientos internos y externos: "|...|son de opinión que Chile ha adquirido como resultado de la guerra el derecho a indemnización por los gastos de ella y que el Perú no puede rehusar al pago." Mientras, el Presidente García Calderón, esposa y dos hijas, permanecían de rehén en la zona más inhóspita y alejada de Chile. Basadre ob. Cit. T. VI, Pág. 267. 


\section{BibLIOGRAFÍA}

ALLENDE, Isabel

2000. La Casa de los Espíritus. Barcelona, Plaza y Janes Editores S.A.

BASADRE GROHMANN, Jorge

1989. Historia de la República. Editorial Internacional. Tercera edición.

\section{BIELSA, Rafael}

1957. Régimen Furídico de Policia. Buenos Aires, Edit. La Ley.

CABANELLAS, Guillermo y Alcalá Zamora.

1982. Diccionario Encidopédico de Derecho Usual. B. Aires, Edit. Heliasta. $15^{\text {a }}$ edición.

Diario Liberación. Lima, abril 16, 2001.

\section{CAEN TE-001-1995}

1995. Planteamientos Doctrinarios y Metodológicos, Desarrollo y Defensa Nacional. Lima, Centro de Altos Estudios Militares, Tomo I.

\section{EINSTEIN, Albert}

1984. Mis Ideas y Opiniones. Edit. S.A., Biblioteca de los Grandes Pensadores, Madrid.

\section{HERODOTO}

s/f Los Nueve Libros de la Hisioria. Urania, Libro Octavo.

\section{HOMO, León}

1959. Perides, una Experiencia de Democracia Dingida. México, Edit. Grijalbo. S. A.

\section{JUSTINIANO}

1986. Instituciones. Lima, Mesa Redonda Editores.

\section{MAQUIAVELO, Nicolás}

2000. El Príncipe. Colección El Comercio de Lima, 2000.

\section{NARANJO MESA, Vladimiro}

2000. Teoria Constitucional e Instituciones Politicas. Santa Fe de Bogotá, Edit. Temis S.A.

PIRENNE, Jacques

1989. Historia Universal. Las Grandes Corrientes de la Historia.
Las corrientes totalitarias. Buenos Aires, Edit. Océano. Traduc. al español de la Cuarta Edic. francesa.

\section{QUISPE CORREA, Alfredo}

1994. Constitución y Defensa Nacional. Lima, Edic. Luis Alfredo.

\section{REED, John}

1985. México Insurgente. La Revolución de 1910. México, Edit SARPE.

\section{SMITH, Louis}

1965. La Democracia y el Poder Militar. Un estudio del civil sobre el'poder militar en los EE.UU. Buenos Aires, Bibliografia Ameba. Segunda Edic.

\section{SOBERÓN Garrido.}

1992-1996. Corrupción Asociada al' Tráfico de Drogas y las Fuerzas Armadas.

\section{TÁCITO}

1982. Anales. Libro Sexto. San Sebastián, TXERTOA EDICIONES.

\section{TOCQQUEVILLE, Alexis de}

1957. La Democracia. México-Buenos Aires, Fondo de Cultura Económica

1963. La Democracia en América. Fondo de Cultura Económica. Segunda Edición en Español.

\section{VOLTAIRE}

1981. Cartas Filosóficas y otros Escritos. Madrid, EDAF Ediciones.

\section{VILLANUEVA, Víctor}

1971. 100 años del Ejército Peruano. Lima, Edit. Juan Mejía Baca.

\section{ZAFFARONI R. Eugenio}

2000. Derecho Penal, Parle General. La Función Pública y su imagen politica. Buenos Aires, Ediar. Segunda Edición.

\section{Otras fuentes:}

Constituciones Politicas de Aménica y de otros Estados Occidentales 